\title{
AIRDOC: SMART MOBILE APPLICATION FOR INDIVIDUALIZED SUPPORT AND MONITORING OF RESPIRATORY FUNCTION AND SOUNDS OF PATIENTS WITH CHRONIC OBSTRUCTIVE DISEASE
}

\author{
Rute Almeida ${ }^{1}$, Cristina Jácome ${ }^{1}$, Diogo Martinho ${ }^{2}$, Pedro Vieira-Marques ${ }^{1}$, Tiago Jacinto ${ }^{1,3,4}$, \\ Ana Ferreira ${ }^{1}$, Ana Almeida ${ }^{2}$, Constantino Martins ${ }^{2}$, Mariana Pereira ${ }^{1,3}$, Ana Pereira ${ }^{1}$, \\ José Valente ${ }^{1,3}$, Rafael Almeida ${ }^{1,3}$, Ana Vieira ${ }^{2}$, Rita Amaral ${ }^{1,4}$, Ana Sá-Sousa ${ }^{1}$, Ivânia Gonçalves ${ }^{1,4}$, \\ Pedro Rodrigues ${ }^{1}$, Magna Alves-Correia ${ }^{1,3}$, Alberto Freitas ${ }^{1}$, Goreti Marreiros ${ }^{2}$, \\ Susana Caldas Fonseca ${ }^{3}$, Altamiro Costa Pereira ${ }^{1}$ and João Almeida Fonseca ${ }^{1,3}$ \\ ${ }^{1}$ CINTESIS - Center for Health Technology and Services Research, Faculty of Medicine, University of Porto, Porto, \\ Portugal; \& MEDCIDS - Department of Community Medicine, Health Information and Decision, Faculty of Medicine, \\ University of Porto, Porto, Portugal \\ ${ }^{2}$ GECAD - Research Group on Intelligent Engineering and Computing for Advanced Innovation and Development, \\ Institute of Engineering - Polytechnic of Porto, Portugal \\ ${ }^{3}$ MEDIDA - Serviços em Medicina, EDucação, Investigação, Desenvolvimento e Avaliação, LDA, Porto, Portugal \\ ${ }^{4}$ Porto Health School, Polytechnic Institute of Porto, Porto, Portugal
}

\begin{abstract}
Current tools for self-management of chronic obstructive respiratory diseases (CORD) are difficult to use, not individualized and requiring laborious analysis by health professionals, discouraging their use in healthcare. There is an opportunity for cost-effective and easy-to-disseminate advanced technological solutions directed to patients and attractive to different stakeholders. The strategy of AIRDOC is to develop and integrate self-monitoring and self-managing tools, making use of the smartphone's presence in everyday life. AIRDOC intends to innovate on: i) technologies for remote monitoring of respiratory function and computerized lung auscultation; ii) coaching solutions, integrating psychoeducation, gamification and disease management support systems; and iii) management of personal health data, focusing on security, privacy and interoperability. It is expected that AIRDOC results will contribute for the innovation in CORD healthcare, with increased patient involvement and empowerment while providing quality prospective information for better clinical decisions, allowing more efficient and sustainable healthcare delivery.
\end{abstract}

\section{KEYWORDS}

mHealth, Self-Monitoring, Self-Management, Individualized Coaching, Remote Monitoring

\section{INTRODUCTION}

Worldwide, the burden of respiratory diseases is extremely high: originates 6 million $(\mathrm{M}) /$ year of premature deaths and over $10 \%$ of all disability-adjusted life-years (Roth et al., 2018). About 400M individuals suffer from chronic obstructive respiratory diseases (CORD) throughout the life cycle, asthma commonly starting at early ages and chronic obstructive pulmonary disease (COPD) from the middle-age onwards. CORD are the third worldwide leading cause of death (non-communicable diseases) and have a considerable impact on patients' quality of life. Patients are continuously at risk of health deterioration, becoming more susceptible to exacerbations, which can cause frequent hospital admissions. Thus, patients with CORD require regular medical check-ups and monitoring of their health status. In Europe, the total annual cost of respiratory diseases amounts to more than $€ 380$ billion (European Respiratory Society, 2013). Traditionally, healthcare is delivered through face-to-face interactions with health professionals. With the growing prevalence of CORD and continuous pressure from healthcare authorities and insurance companies, an increasing number of patients are being managed at home in their own environment and most of the time being left alone with traditional 
self-management materials (books, leaflets, videos, and web-based technology). Now more than ever, technological developments empower patients to self-monitoring and management their disease. Smartphones, in addition to the advantages of being portable, personal, connected, affordable and with increasing computational power, may now be found in almost every home and person - including older persons, who progressively have more digital literacy. This creates a clear opportunity for the development of customized mobile health (mHealth) solutions. Tools taking advantage of the smartphone embedded sensors, with no external devices, would be easier to integrate into everyday lives and to disseminate without additional costs (Majumder and Deen, 2019).

For successful management of chronic diseases, sustained adoption of recommended behavior, including adherence to prescribed medication, regular monitoring of symptoms and healthy lifestyles is decisive. Automatic systems, designed to change and/or reinforce, attitudes or behaviors, namely based on the persuasive system design model, have shown to be useful in helping people to change and improve their behavior (Oinas-kukkonen, 2009; Gorini, Caiani and Pravettoni, 2020). Coaching solutions delivered through smartphones (mCoaching) appear to be ideal to deliver both simple and effective self-management interventions and to support recommended behavior, while maintaining or improving quality of care and reducing costs. These solutions allow the combination of data gathering and processing, gamification elements for user engagement and support to behaviors change. Moreover, there is evidence that healthcare delivery through health technologies has beneficial effects on chronic disease management, including CORD (Deterding et al., 2011; Bashshur et al., 2014; Tinschert et al., 2017; Watson, Tribe and Shennan, 2019). However, solutions currently available do not take full advantage of the available technology, are not supported by clinical evidence and/or lack clinical validation (Majumder and Deen, 2019). Different studies have shown patients with CORD have interest in and willingness to use information technologies to help in the management of their disease (Fonseca et al., 2006; Khurana et al., 2016; Dumais et al., 2019). In addition, patients' interest in real-time tracking of health status and progress, reminders, positive reinforcement and support have been reported (Simpson et al., 2017). Moreover, regarding a mHealth intervention to manage COPD healthcare professionals (pharmacists, nurses, and physicians) agreed on its potential health benefits for patients (Alwashmi et al., 2019). Both patients and healthcare professionals, reported "overwhelming support for mHealth to assist asthma self-management". Patients referred monitoring over time and data collection to share with healthcare teams as the more relevant features, while healthcare professionals preferred the deterioration alerts and the advises for seeking medical attention. Nevertheless, barriers such as the credibility of the systems, technical issues related to interoperability problems and the requirement of high-speed connections, as well as privacy and confidentiality concerns, need to be addressed. mHealth technologies for CORD should involve monitoring and managing signs and symptoms of the disease, while coaching solutions are urgently needed to empower patients to recognize the early signs of exacerbations and develop skills to better manage their disease.

AIRDOC project (2018-2021) is developing technologies to cope with these needs, which will be delivered in an integrated mHealth system. It is also part of the ITEA 3 - 16040 PHE - Personal Health Empowerment project, through the use case on CORD. PHE international consortium includes a total of eight partners from Portugal, Spain, Belgium and Turkey. The key consortium members were identified by the necessary competencies. For the success of AIRDOC project, it is important to take advantage of the previous experience in the development of the clinical decision support system FENO Interpretation Aid (CORD diagnostic) (Jacinto, 2010), the mobile application (app) m.CARAT for asthma and rhinitis self-management (Burnay et al., 2013) and the Inspirers brand products - InspirerMundi (Jácome et al., 2017), an app for asthma symptoms and medication adherence monitoring; and InspirersArcade (Almeida et al., 2020), a microphone spirometry serious game. The AIRDOC system is integrable into the Inspirers brand.

\section{CONCEPT AND PROPOSED SOLUTION}

Traditional healthcare has improved the quality of care through evidence-based diagnostic and treatment procedures. However, the current system is reactive and process-oriented, treating patients with predefined clinical pathways, often ignoring patients' individual needs and capabilities. Additionally, healthcare tends to be more often directed for patients in acute (reactive) state, rather than timely assessing risks and preventing adverse (proactive) health outcomes. Technological developments combined with the ubiquity of smartphones, 
the potential of their sensors (e.g. microphone, camera) and computational power, allowing advanced processing implementations and communication capabilities, create the opportunity to develop smartphone-based monitoring solutions, without additional devices, integrated into the everyday lives of people with CORD. The current healthcare for CORD creates an opportunity for secondary prevention and lifestyle mCoaching applications to effortlessly reach a large number of people. New perspectives on psychology and gamification can be used for engaging people for more time, as required to achieve and maintain health goals.

In this regard, the AIRDOC system is developing and validating a health self-monitoring and coaching suite for people with CORD, based on mobile devices and their integrated sensors. By using these low-cost technologies in order to implement patient-centered healthcare, the proposed system has the potential to contribute to a more personalized, efficient and innovative CORD management, and be useful for patients, healthcare professionals and healthcare services alike. The proposed solution is outlined in Figure 1.

With the patient at the center of this paradigm, AIRDOC aims to empower patients with CORD for self-monitoring and management through a mobile app, which is the most visible face of a more complex integrated underlying system. The app allows the acquisition of several self-reported parameters of the patient's characteristics, their behaviors and circumstances. The sensors embedded on the smartphone will be central for data collection. The coaching component combines processed data with a clinical knowledge-base to provide information and suggest recommended behaviors / actions to the patient via the app. An interface for accessing relevant clinical information, always authorized by the patient, provides a privileged tool for the healthcare professional to access patient data and interact with the patient if needed. AIRDOC adopts good practices regarding health information related standards, privacy and confidentiality to promote interoperability and to guarantee security throughout (Ferreira, Almeida and Muchagata, 2020).

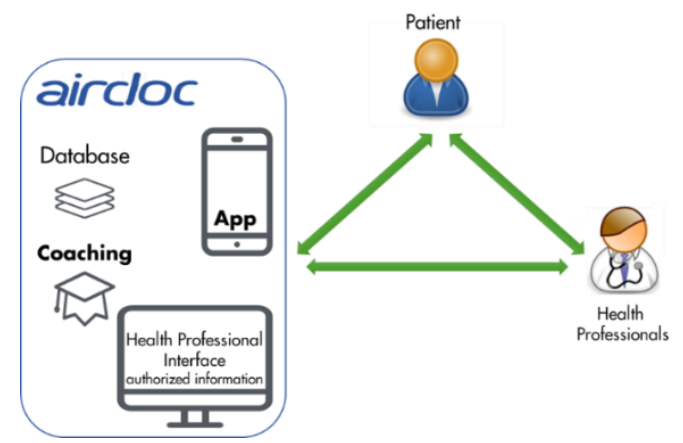

Figure 1. Solution proposed by AIRDOC

\subsection{Goals and Innovation}

AIRDOC is developing a set of information technologies with innovative and efficient approaches to patient's remote monitoring and chronic disease management support. It is not intended to support the CORD diagnosis or initial treatment, but to complement the delivery of high-quality healthcare.

Current respiratory function monitoring tools provide low-sensitivity parameters limiting its widespread use for monitoring patients with CORD. In this sense, AIRDOC aims to 1) deploy innovative, effective and reliable technologies 1.1) for self-monitoring by patients with CORD, based on existing sensors in the smartphone and 1.2) to extract parameters for characterization of respiratory function and computerized lung auscultation (Technology readiness levels - TRL 2-4). These technologies coupled with smartphone abilities can assist in managing data and promote its flow between patients and healthcare professionals and services, while promoting more informed and shared disease management.

Intelligent individualized support solutions, involving patients with chronic illnesses in self-management of disease signs and symptoms, are needed and will facilitate the early recognition of signs of acute illness and the development of skills to better manage their disease. Therefore, AIRDOC is proposing 2) an intelligent individualized coaching component (TRL 2-4), supported and driven by clinical evidence. These strategies are expected to motivate sustained behavioral changes in patients with CORD, with recognizable health benefits, and to provide an innovative solution for the efficient management and modernization of healthcare delivery, with improved clinical outcomes. In order to effectively deliver the monitoring technologies and coaching 
solutions to the patient with CORD and healthcare services, AIRDOC 3) produces an integrated smartphone app-based system (TRL 2-4) that implements the innovative technologies developed in 1) and 2). This digital health app will gather patients' information, through self-monitoring features, and the system will allow a more informed physician-patient interaction, that creates the opportunity for the delivery of additional, high quality, innovative healthcare, with great potential for improving health systems.

In this context, the privacy and security of health information are essential. Thus, AIRDOC 4) applies a new access control model that enables more personalized, secure, and context-sensitive access. This access control accounts for the risk and visualization requirements of each situation (TRL 2-4) and meets the needs of the security and privacy for the user and business. To ensure that the innovative technologies developed are suited to the needs and expectations of individuals with CORD, AIRDOC will 5) validate and test these technologies with end-users in a real environment. An initial validation phase in a clinical laboratory environment more focused on the feasibility, usefulness and usability of the app, and a second testing phase in the community, focusing on the validation and assessment of the effect magnitude (TRL 5-6).

\section{CURRENT SOLUTIONS}

The currently available solutions for CORD self-monitoring based on mobile applications rely mostly data collection through devices connected to smartphones and not on the use of its embedded sensors (Tables 1 and 2). Some portable spirometers with connection to the smartphone are available (MIR, no date; Larson et al., 2013; Tran, Ngo and Pham, 2015; Thap et al., 2016; AioCare, 2018; Hernández et al., 2018; Inofabheath, 2020). These spirometers were considered promising technologies due to the high degree of innovation, potential impact and because they were considered acceptable by patients. A number of competing solutions for automatic respiratory function analysis using smartphones have also emerged, such as SpiroSmart (USA) (Hernández et al., 2018) and the BKSpiro (Vietnam) (Tran, Ngo and Pham, 2015). However, these solutions are only being developed in an academic context and are not commercially available. SpiroSmart is in a more mature phase of development, being currently waiting for approval by the Food and Drug Administration. However, it lacks the ability to analyze data in real-time and its performance depends on customization to the patients' characteristics (Hernández et al., 2018). Regarding computerized lung auscultation, we did not find solutions that use only the built-in smartphone sensors. Solutions integrating the connection of a stethoscope to a smartphone, such as CliniCloud Stethoscope (CliniCloud, 2019) (USA and Australia) and the methods proposed by Chamberlain et al (Chamberlain et al., 2015) (USA and India) have been described but are not currently commercially available. The same stands for ResAppDx, which is already certified as medical device (CE mark) (States and Resapp, 2017). ResAppDx intends to support the diagnosis of respiratory diseases using respiratory and cough sounds collected without the need for external devices.

To the best of our knowledge, solutions similar to those proposed by AIRDOC are not currently available. AIRDOC can be one of the first solutions based solely on software and on the use of smartphone embedded sensors, avoiding the use of additional equipment connected equipment to mobile devices. The already developed lung function acquisition system includes feedback on the quality of the maneuver and the Portuguese version is currently freely available in Google Play store (Almeida et al., 2020). The technologies integrated by AIRDOC as software-only solutions, with no additional costs associated, have a promising potential of innovation, allowing easy and wide spread. This is supported by the review of the National Institute for Health Research Horizon Scanning Research and Intelligence Center Work Program, where they evaluated and selected the latest technologies of respiratory function monitoring as some of the most promising tools for the diagnosis and management of patients with COPD (Dixon et al., 2016).

\section{AIRDOC SYSTEM}

The AIRDOC system architecture is outlined in Figure 2. The mobile app allows the patient to input data that is then transmitted to a server that accommodates data storage and processing, coaching engine and system analytics. A healthcare professional interface allows access to data whenever authorized by the patient, the insertion of additional health information (e.g. diagnostic tests). An internet connection is required for communication with the server, however the local database on the smartphone device allows the basic offline use, with the ability to gather data, create and receive reminders. Once online, the data will be sent to the server and coaching recommendations will be given, if necessary. 
Table 1. Existing CORD monitoring solutions for evaluation lung function using smartphones. FVC - Forced vital capacity, FEV1 - forced expiratory volume in the first second. PEF - peak expiratory flow

\begin{tabular}{|c|c|c|c|c|}
\hline Product & Main Features & Validation & Strengths & Weaknesses \\
\hline $\begin{array}{l}\text { AioCare - } \\
\text { MySpiroo, } \\
\text { HealthUp, Poland } \\
\text { (AioCare, 2018) }\end{array}$ & $\begin{array}{l}\text { Real time Spirometry } \\
\text { Decision support for COPD } \\
\text { diagnosis } \\
\text { Exacerbation predictive models }\end{array}$ & $\begin{array}{l}\text { Several studies } \\
\text { including one with } \\
215 \text { screened } \\
\text { patients by } 21 \\
\text { general } \\
\text { practitioners }\end{array}$ & $\begin{array}{l}\text { Air quality } \\
\text { monitoring } \\
\text { Digital assistant } \\
\text { Medication } \\
\text { reminders } \\
\text { Doctor app }\end{array}$ & $\begin{array}{l}\text { Bluetooth connected } \\
\text { external devices } \\
\text { required }\end{array}$ \\
\hline $\begin{array}{l}\text { Air-Smart } \\
\text { Spirometer } \\
\text { Nuvoair AB, Spain } \\
\text { and Sweden } \\
\text { (Hernández et al., } \\
\text { 2018) }\end{array}$ & Real time Spirometry & $\begin{array}{l}\text { A two-centers } \\
\text { study with } 200 \\
\text { patients (Spain) }\end{array}$ & $\begin{array}{l}\text { Automated } \\
\text { treatment plan. } \\
\text { Feedback and } \\
\text { instructions for } \\
\text { maneuver } \\
\text { correction. }\end{array}$ & $\begin{array}{l}\text { External devices } \\
\text { required }\end{array}$ \\
\hline $\begin{array}{l}\text { BKSpiro (Tran, Ngo } \\
\text { and Pham, 2015) } \\
\text { Hanoi University of } \\
\text { Science } \\
\text { and Technology - } \\
\text { Vietnam }\end{array}$ & $\begin{array}{l}\text { Lung function based in Short- } \\
\text { time Fourier transform from } \\
\text { smartphone microphone } \\
\text { Extraction of the FVC, FEV1, } \\
\text { PEF, and FEV1/FVC. }\end{array}$ & $\begin{array}{l}\text { No validation with } \\
\text { patients, data from } \\
17 \text { university } \\
\text { students was used }\end{array}$ & $\begin{array}{l}\text { No need for } \\
\text { external devices }\end{array}$ & $\begin{array}{l}\text { Limited } \\
\text { accuracy reported }\end{array}$ \\
\hline $\begin{array}{l}\text { Spirohome, } \\
\text { inofabhealth, } \\
\text { Turkey } \\
\text { (Inofabheath, 2020) }\end{array}$ & Real time Spirometry & Not found & $\begin{array}{l}\text { Progress track. } \\
\text { Bluetooth } \\
\text { connected. } \\
\text { Share results with } \\
\text { physician }\end{array}$ & $\begin{array}{l}\text { External devices } \\
\text { required. } \\
\text { Limited information } \\
\text { on performance }\end{array}$ \\
\hline $\begin{array}{l}\text { Smart One, Medical } \\
\text { International } \\
\text { Research, Italy } \\
\text { (MIR, no date) }\end{array}$ & Real time FEV1 and PEF & $\begin{array}{l}\text { Performance tests } \\
\text { according to the } \\
\text { American } \\
\text { Thoracic Society } \\
\text { standards }\end{array}$ & $\begin{array}{l}\text { Bluetooth } \\
\text { connected. } \\
\text { Symptoms } \\
\text { registration }\end{array}$ & $\begin{array}{l}\text { External devices } \\
\text { required } \\
\text { Limited information } \\
\text { on performance }\end{array}$ \\
\hline $\begin{array}{l}\text { SpiroSmart (Larson } \\
\text { et al., 2013) } \\
\text { University of } \\
\text { Washington - USA }\end{array}$ & $\begin{array}{l}\text { Lung function based in Short- } \\
\text { time Fourier transform from } \\
\text { smartphone microphone } \\
\text { Extraction of the FVC, FEV1, } \\
\text { PEF, and FEV1/FVC }\end{array}$ & $\begin{array}{l}\text { Validation with } 52 \\
\text { subjects reporting } \\
\text { having none or } \\
\text { only mild lung } \\
\text { conditions }\end{array}$ & $\begin{array}{l}\text { No external } \\
\text { devices. } \\
\text { Consistent } \\
\text { measures of } \\
\text { FEV1, PEF, and } \\
\text { FEV1/FVC } \\
\text { Results shareable } \\
\text { with physician }\end{array}$ & $\begin{array}{l}\text { No verification, } \\
\text { incentives or } \\
\text { motivations for } \\
\text { correct maneuver } \\
\text { execution } \\
\text { No real time } \\
\text { Performance depends } \\
\text { on personalization. } \\
\text { Decreased accuracy in } \\
\text { FVC even after } \\
\text { personalization } \\
\text { No commercial or } \\
\text { publicly available } \\
\text { version found } \\
\text { (academic only) }\end{array}$ \\
\hline $\begin{array}{l}\text { Wonkwang } \\
\text { University School of } \\
\text { Medicine, Korea } \\
\text { (Thap et al., 2016) }\end{array}$ & $\begin{array}{l}\text { Lung function from } \\
\text { smartphone microphone based } \\
\text { in frequency complex } \\
\text { demodulation } \\
\text { Extraction of the FVC, FEV1, } \\
\text { PEF, and FEV1/FVC }\end{array}$ & $\begin{array}{l}\text { Validation with } 13 \\
\text { healthy subjects } \\
\text { and } 13 \text { COPD } \\
\text { patients }\end{array}$ & $\begin{array}{l}\text { Able to estimate } \\
\text { accurately } \\
\text { FEV1/FVC }\end{array}$ & $\begin{array}{l}\text { External devices } \\
\text { required. } \\
\text { Limited results for } \\
\text { FVC, FEV1, and PEF } \\
\text { No commercial or } \\
\text { publicly available } \\
\text { version found } \\
\text { (academic only) }\end{array}$ \\
\hline
\end{tabular}


Table 2. Existing CORD monitoring solutions for lung auscultation assessment

\begin{tabular}{|c|c|c|c|c|}
\hline Product & Main Features & Validation & Strengths & Weaknesses \\
\hline $\begin{array}{l}\text { CliniCloud } \\
\text { Stethoscope USA } \\
\text { and Australia }\end{array}$ & $\begin{array}{l}\text { Computerized } \\
\text { stethoscope }\end{array}$ & Not found & $\begin{array}{l}\text { Sound recording at medical } \\
\text { diagnostic quality } \\
\text { Results shareable with physician }\end{array}$ & $\begin{array}{l}\text { External devices } \\
\text { required } \\
\text { No automatic } \\
\text { analysis } \\
\text { Turned off at } \\
30 / 09 / 2019\end{array}$ \\
\hline $\begin{array}{l}\text { Mobile } \\
\text { Stethoscope MIT, } \\
\text { USA and India } \\
\text { (Chamberlain } e t \\
\text { al., 2015) }\end{array}$ & $\begin{array}{l}\text { Computerized } \\
\text { stethoscope }\end{array}$ & $\begin{array}{l}\text { Validation } \\
\text { with } 38 \\
\text { patients, } 11 \\
\text { auscultation } \\
\text { locations }\end{array}$ & $\begin{array}{l}\text { Sound recording at medical } \\
\text { diagnostic quality } \\
\text { Automatic detection of wheeze } \\
\text { sounds }\end{array}$ & $\begin{array}{l}\text { Connected external } \\
\text { device } \\
\text { No commercial or } \\
\text { publicly available } \\
\text { version found } \\
\text { (academic only) }\end{array}$ \\
\hline $\begin{array}{l}\text { ResAppDx } \\
\text { (States and } \\
\text { Resapp, 2017) }\end{array}$ & $\begin{array}{l}\text { Smartphone- } \\
\text { based machine } \\
\text { learning } \\
\text { algorithms } \\
\text { from cough } \\
\text { and respiratory } \\
\text { sounds }\end{array}$ & $\begin{array}{l}\text { Validation } \\
\text { with } 979 \\
\text { patients } \\
\text { with acute } \\
\text { or chronic } \\
\text { respiratory } \\
\text { diseases }\end{array}$ & $\begin{array}{l}\text { No external devices required. } \\
\text { Accurately identified acute } \\
\text { exacerbations identifications in } \\
\text { patients with COPD or asthma, } \\
\text { and screening for COPD in a } \\
\text { broad general population } \\
\text { CE mark, as medical device }\end{array}$ & $\begin{array}{l}\text { Limited information } \\
\text { on performance and } \\
\text { methodology } \\
\text { No commercial or } \\
\text { publicly available } \\
\text { version found } \\
\text { (academic only) }\end{array}$ \\
\hline
\end{tabular}

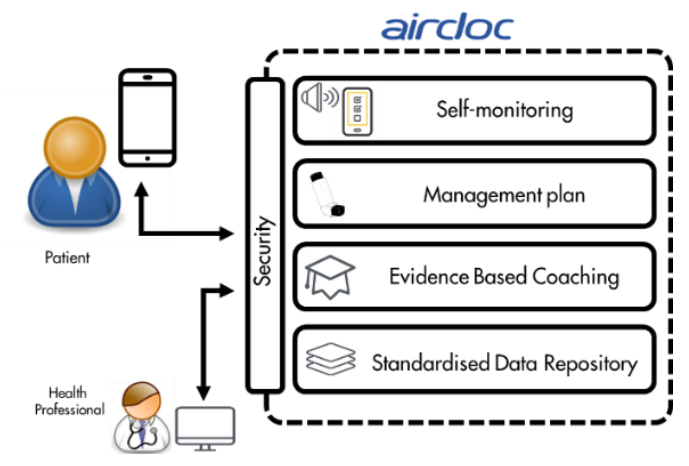

Figure 2. AIRDOC System Architecture

A security layer is in charge of authentication and authorization, managing all data exchanges in-between modules, by using OAuth 2.0 and a self-hosted identity server with openID framework, to promote security and trust. A secure and flexible delegation model for sharing health data between patients and healthcare professionals is included within that security layer (Almeida, Vieira-Marques and Ferreira, 2020). The delegation feature has been devised and prototyped within AIRDOC, to help empower the patient to perform a fine-grained control to what data can be shared, to whom and for how long. On the whole, the security layer was devised and developed with the main aim to be modular and independent, in order to be easily adapted to similar scenarios. Moreover, HL7 FHIR standard for health care data modeling and exchange is used at all levels, from app backend to health data storage, and used for data exchange between system modules. Using this approach, the system promotes interoperability allowing for semantic rich data storage, sharing and reuse, while guaranteeing data quality and security. The system takes advantage of the embedded sensors of the smartphones, with no external devices required for full use and mainly relying in self-reporting. The integration of user authorized data from external monitoring devices, other electronic health recordings and mobile apps data is possible, especially for systems also using HL7 FHIR standard. Information from other sources, such as air quality and meteorological data, may also be retrieved when subscribed. Individualized support based on the data provided by the patient and healthcare professional, clinical evidence and guidelines will be delivered, following the persuasive system design model principles of personalization, self-monitoring, strategies of reminders and suggestions, with trustworthiness, credibility and verifiability (Oinas-kukkonen, 2009). 
Taking advantage of previous experience of the consortium in clinical decision support system and mHealth, the app integrates some of the previous developed features, namely from InspirerMundi app (Jácome et al., 2017). The main modules for self-monitoring, management plan and evidence based coaching, which together with the data repository constitute the AIRDOC system, are detailed in the next subsections.

\subsection{Self-Monitoring Module}

The system mainly relies on data inserted in the AIRDOC app. To achieve personalization, the patient's relevant characteristics, previous diagnoses and circumstances should be retrieved. The system will suggest reporting of symptoms, exacerbations, health services use, habits and burden factors, in order to follow-up the CORD evolution. Validated questionnaires, such as the Control of Allergic Rhinitis and Asthma Test (CARAT) (Thap et al., 2016), screening tests (Sá-Sousa et al., 2019), and other patient-reported outcomes may be used.

The embedded microphone will be used to acquire the sounds of forced expiratory maneuvers (microphone spirometry) and computerized lung auscultation. The processing of the sound includes automatic quality check in particular regarding the correct performance of the maneuver, as well as extraction of features with potential clinical value (Fonseca et al., 2015; Pinho et al., 2018; Almeida et al., 2019, 2020). These sounds can also be made available to the healthcare professional for further analysis. Automatic metrics can be immediately reported to the patient whenever available, and both summaries and graphical reports will be produced, allowing to monitor the health status and changes. Healthcare professionals, upon patient authorization, will receive relevant information for remote monitoring actions and decision making.

Health professionals indicated by the user will be able to complete the data reported by the patient adding details on diagnostic exams and health services use among others, using their specific interface.

\subsection{Management Plan Module}

The setup of the management plan may be introduced manually by the patient on the app, or defined in the healthcare professionals' interface. Both patient and healthcare professional can approve or suggest editions over the plan introduced by the other. Based on this plan, personalized notifications (reminders) will be generated for medicine intake, healthy behaviors and other health interventions.

The long-term goal of CORD management is to reduce symptoms and the severity and frequency of exacerbations, to which those patients are prone to. Adequate medication adherence is critical for that purpose, in particular to inhaled medication, that is the cornerstone of CORD effective treatment. AIRDOC is taking advantage of previously developed tools for objective monitoring of medication adherence. An enhanced version of the image-based dose recognition developed for InspirerMundi app will be integrated into the AIRDOC app (Vieira-Marques et al., 2020). Reports and statistics on the medication adherence will be available to the patient, being shareable with the health professionals.

In spite of being designed for medication related to CORD, the tools of self-management can also be used to register and monitor adherence to any medication included in the treatment plan for any comorbidity. Different information would be shareable with different healthcare professionals.

\subsection{Coaching Module}

As a patient-centered system, AIRDOC will produce individualized support for self-management of CORD, giving recommendations and positive reinforcement of adequate behaviors. In this context, the coaching module has been proposed (Vieira et al., 2019) and further extended to process data from the self-monitoring module on the app and from healthcare professional interface. A rule-based system using JBoss Drools (JBoss, 2020) framework has been developed with the main goal to combine clinical knowledge-base with patient data to detect events and produce adequate recommendations. The alignment of those recommendations with the clinical evidence and updated guidelines is of utmost importance for the credibility of the system and the usefulness of the coaching. Furthermore, the system will monitor patients' behaviors and clinical data to match the suggestions to the user's profile. Additionally, the coaching component is expected to respond dynamically to measurements, interactions and environmental factors by selecting the coaching activities that best suit the patient's condition. In the specification of these algorithms, based on patient behavior and data collected, different activities can be proposed to promote wellbeing and ensure adherence to the treatment plan. The 
expected outcome is the definition of personalized coaching plans designed with healthcare professional support and proposed to the patient. These plans include a set of goals associated to a specific topic of CORD management, with different difficulty levels. The patient's actions will be tracked and successful/unsuccessful interaction (achieved/ non-achieved goals) will result in an automatic update of established goals for upcoming days with increased or decreased difficulty.

The patient will be able to express satisfaction with the recommendations and register events representing the compliance with them. Relevant interactions between the patient and the AIRDOC system will be analyzed in the coaching module to understand and automatically adapt future interactions based on user preferences and progress for any established coaching plan. Reports and statistics on the recommendations produced, patient response, completed plans, rate of compliance, achieved goals, and user progress will be also available.

\section{PILOT STUDIES DESIGN}

The conduction of studies with real patients with CORD (adults, including older people $\geq 65$ years) to validate the prototype of the integrated system and its modules, and evaluate the final version is crucial.

Ethics and administrative approvals in the institutions involved in data collection and patient recruitment will be obtained. Patients will sign a written informed consent prior to any data collection. In addition to following the directions outlined in the Portuguese Data Protection legislation on the processing of personal and identifiable patient data (Law No. $67 / 98$ of 26 October 1998, DR - I Series - A, No. 247), AIRDOC will also, under the European Data Protection Regulation (Regulation (EU) 2016/679 of 27 April 2016, Official Journal of the European Union, L119, 59), present in a clear and objective manner who is going to collect, store and able to access the data. Moreover, whenever there are any changes to those procedures, the patient will be fully and promptly informed and will have the chance to opt-out at any time.

Pilot studies will be performed in three phases. The initial two validation phases will have a smaller scale (minimum 12 adults) and be more focused on the feasibility, usefulness, usability and acceptance of the system. This was submitted to an ethical commission of a hospital and waits for authorization. The third phase is a medium term prospective real-life environment, focusing on validation and estimation of the magnitude of the effect of the app use and personalized coaching on symptoms and exacerbations with at least 70 adults. In spite of the detailed characteristics of the pilot studies are still to be finalized, the main design will be as follows.

\subsection{Cross-Sectional Validation}

In the first pilot study, the prototype of the app, particularly the self-monitoring technologies, will be validated in a clinical environment. This study will be conducted with a minimum of 12 adults with CORD. In a single visit, recruited patients will be informed on how to use the prototype app and will be asked to use it to register data, namely, acquisition of respiratory function parameters and sounds, symptoms and treatment plans. A healthcare professional will then evaluate the respiratory parameters by standard procedures (e.g., spirometry and lung auscultation) to allow further validation of measurements. Results will be treated statistically and will be used to introduce adjustments in subsequent studies. Patient feedback will be considered to refine and improve the developed mobile functionalities.

\subsection{Short Term Prospective Validation}

This pilot intends to evaluate the integrated system, namely the data acquisition and processing and the coaching components, by patients with CORD in a real-world setting. A minimum of 12 adults with CORD are expected to be recruited and will have the same initial visit described in the cross-sectional validation. Additionally, they will be invited to use the prototype of the integrated system to self-monitor their disease in the community for one week. Patients will be instructed by a healthcare professional to routinely input data to the app, including the recording of respiratory sounds in their usual context (e.g., home, community) and also to adhere to the coaching component. After one week of use, patients will be invited to participate in a focus group and answer usability questionnaires. Results will be processed and can be used to make adjustments to the final study pilot. Users' feedback will be used to refine and improve the system. 


\subsection{Medium Term Prospective Assessment}

The last pilot study intends to estimate the magnitude of the effect of the developed product on disease management, including the reduction of symptoms and exacerbations. A minimum sample of 70 adults with CORD will be recruited for a 4-month observational study conducted in the community. At the initial visit, similarly to the first pilots, all patients will be instructed to routinely use the integrated system in their daily life. A subset of patients will receive instructions to adhere to the coaching component, while the remaining will not receive this individualized support. This design will not only allow to compare patients throughout the use of the integrated system but also to have a rough estimate of the specific effect of mCoaching, apart from the effect of self-monitoring. The data generated by this study will also create new opportunities for research and development of innovative healthcare. In particular, respiratory sound recordings will be organized and made available to the scientific community in the form of a fully anonymized signal database.

\section{EXPECTED RESULTS}

The AIRDOC project is expected to produce several tools and products, as an integrated mHealth system. The clinical knowledge-base that encompasses current guidelines, the clinical evidence rule editor to facilitate knowledge-base updates, the computational model for individualized coaching of patients with CORD, based on clinical evidence gathered in the knowledge-base and the delegation model to provide secure health data sharing were completed in 2019. The system architecture was defined and the security layer with the delegation model was implemented. The coaching engine, based on the knowledge-base constructed, is fully functional. A prototype app including forced expiratory maneuver and lung auscultation acquisition systems, and a questionnaire (as prove of concept) is available for testing monitoring data collection. Both monitoring and coaching modules are using HL7 FHIR standards for data exchange, interacting with data repository. Secure sharing of patients' clinical data with the healthcare professionals, allowing better, informed clinical decisions, and, ultimately, making healthcare more efficient and sustainable.

During 2020 are expected to be finalized the prototype of monitoring data acquisition implemented in the app, including the different patient reported outcomes and tolls for coaching personalization, and the computational models to design dynamic coaching plans and associated goals that can track and evaluate patient progress. These will allow to have full prototypes of the mobile self-monitoring system and of individualized mCoaching to be tested. The health professional interface will also be completed.

By the end of project (2021) the validated self-monitoring and self-managing system for patients with CORD, including individualized coaching should be ready to further testing and clinical care.

\section{CONCLUSION}

AIRDOC aims to develop and validate a set of information and communication technologies with innovative and efficient approaches for the remote monitoring and self-management of patients with CORD. These mHealth technologies will:

- empower the patient with CORD to self-monitor the disease, with effective ways, supporting early identification of risks and prevention of exacerbations;

- produce and deliver clinical-based recommendations, through individualized coaching;

- support the patient in the self-management of CORD, promoting treatment adherence and the adoption of healthy behaviors;

- provide updated information to the healthcare team, promoting efficient and safe communication with the patient and facilitating the implementation of timely interventions.

AIRDOC is expected to contribute to the delivery of digital health services and innovation in remote patient monitoring technologies. The use of the AIRDOC system should provide greater involvement and empowerment of patients in their treatment and collects quality prospective data. Therefore, is expected to have a significant impact and innovation in CORD health services, providing support for shared clinical decision making, and making healthcare more effective, efficient and sustainable. Moreover, in spite of being designed for CORD treatments, some developed tools could also be used to register and monitor the treatments of any comorbidity, or adapted for other chronic diseases. 


\section{ACKNOWLEDGEMENT}

This work is supported by project NORTE-01-0247-FEDER-033275, financed by the North Portugal Regional Operational Programme (NORTE 2020), under the PORTUGAL 2020 Partnership Agreement, and through the European Regional Development Fund (ERDF). AIRDOC is with ITEA 316040 PHE - Personal Health Empowerment project consortium. R. Almeida is supported through the operation POCI-01-0145-FEDER-029130 (mINSPIRERS- mHealth to measure and improve adherence to medication in chronic obstructive respiratory diseases - generalisation and evaluation of gamification, peer support and advanced image processing technologies) funded by the COMPETE2020 and by National Funds through FCT (Fundação para a Ciência e a Tecnologia). A. Ferreira is also with TagUBig - Taming Your Big Data (IF/00693/2015) from Researcher FCT Program funded by National Funds through FCT.

\section{REFERENCES}

AioCare (2018) MySpiroo. Available at: https://attendris.com/wpcontent/uploads/2018/05/RIS2018_DigitalTech_HealthUp.pdf?utm_source=RIS_Agenda\&utm_medium=Presentatio n\&utm_campaign=RIS_2018\&utm_content=RespiratoryInnovation (Accessed: 3 December 2019).

Almeida, R. et al. (2019) 'Quality assessment and feedback of Smart Device Microphone Spirometry executed by children', in Proceedings of IEEE 6th Portuguese Meeting on Bioengineering (ENBENG). IEEE, p. 8692452. doi: 10.1109/ENBENG.2019.8692452.

Almeida, R. et al. (2020) 'Automatic Quality Assessment of a Forced Expiratory Manoeuvre Acquired with the Tablet Microphone', in IFMBE Proceedings MEDICON 2019, pp. 1394-1398. doi: 10.1007/978-3-030-31635-8_170.

Almeida, R., Vieira-Marques, P. and Ferreira, A. (2020) 'Patients to mobilize their data: Secure and flexible mHealth delegation', in ICISSP 2020 - Proceedings of the 6th International Conference on Information Systems Security and Privacy, pp. 552-560. doi: 10.5220/0008972905520560.

Alwashmi, M. F. et al. (2019) 'Perceptions of Health Care Providers Regarding a Mobile Health Intervention to Manage Chronic Obstructive Pulmonary Disease: Qualitative Study', JMIR mHealth and uHealth, 7(6), p. e13950. doi: 10.2196/13950.

Bashshur, R. L. et al. (2014) 'The Empirical Foundations of Telemedicine Interventions for Chronic Disease Management', Telemedicine and e-Health, 20(9), pp. 769-800. doi: 10.1089/tmj.2014.9981.

Burnay, E. et al. (2013) 'Challenges of a mobile application for asthma and allergic rhinitis patient enablement-interface and synchronization.', Telemedicine journal and e-health, 19(1), pp. 13-8. doi: 10.1089/tmj.2012.0020.

Chamberlain, D. et al. (2015) 'Mobile stethoscope and signal processing algorithms for pulmonary screening and diagnostics', Proceedings of the 5th IEEE Global Humanitarian Technology Conference, GHTC 2015. IEEE, pp. 385-392. doi: 10.1109/GHTC.2015.7344001.

CliniCloud (2019) CliniCloud Stethoscope. Available at: https://clinicloud.com/store/stethoscope/ (Accessed: 2 September 2019).

Deterding, S. et al. (2011) 'Gamification: Using game design elements in non-gaming contexts', in Conference on Human Factors in Computing Systems - Proceedings. New York, New York, USA: ACM Press, pp. 2425-2428. doi: $10.1145 / 1979742.1979575$.

Dixon, L. C. et al. (2016) 'New and emerging technologies for the diagnosis and monitoring of chronic obstructive pulmonary disease', Chronic Respiratory Disease, 13(4), pp. 321-336. doi: 10.1177/1479972316636994.

Dumais, K. M. et al. (2019) 'Preferences for Use and Design of Electronic Patient-Reported Outcomes in Patients with Chronic Obstructive Pulmonary Disease', The Patient - Patient-Centered Outcomes Research. doi: 10.1007/s40271019-00376-9.

European Respiratory Society, S. (2013) 'The economic burden of lung disease', in Gibson, G. et al. (eds). European Respiratory Society, pp. 16-27.

Ferreira, A., Almeida, R. and Muchagata, J. (2020) 'How Secure Is Your Mobile Health?', in IFMBE Proceedings MEDICON 2019, pp. 1377-1384. doi: 10.1007/978-3-030-31635-8_168.

Fonseca, J. A. et al. (2006) 'Asthma patients are willing to use mobile and web technologies to support self-management', Allergy: European Journal of Allergy and Clinical Immunology. Munksgaard International Publishers, 61(3), pp. 389-390. doi: 10.1111/j.1398-9995.2006.01016.x.

Fonseca, J. F. et al. (2015) 'Automatic Analysis of Lung Function Based on Smartphone Recordings', Biomedical engineering systems and technologies BIOSTEC 2015, 574, pp. 390-402. doi: 10.1007/978-3-319-27707-3. 
Gorini, A., Caiani, E. G. and Pravettoni, G. (2020) 'Psycho-cognitive Factors Orienting eHealth Development and Evaluation', in P5 eHealth: An Agenda for the Health Technologies of the Future. Cham: Springer International Publishing, pp. 109-121. doi: 10.1007/978-3-030-27994-3_7.

Hernández, C. R. et al. (2018) 'Validation of the portable Air-Smart Spirometer1. Hernández CR, Fernández MN, Sanmartín AP, Roibas CM, Domínguez LC, Rial MIB, et al. Validation of the portable Air-Smart Spirometer. PLoS One. 2018;13(2):1-11.', PLoS ONE, 13(2), pp. 1-11. doi: 10.1371/journal.pone.0192789.

Inofabheath (2020) spirohome. Available at: https://spirohome.io (Accessed: 3 December 2019).

Jacinto, T. (2010) A Decision Support System for Exhaled Nitric Oxide Values Model and evaluation. Faculty of Medicine of University of Porto.

Jácome, C. et al. (2017) 'Inspirers: An app to measure and improve adherence to inhaled treatment', in Proceedings of the International Conference on E-Health, EH 2017 - Part of the Multi Conference on Computer Science and Information Systems 2017.

JBoss (2020) Drools - Business Rules Management System (Java ${ }^{T M}$, Open Source). Available at: https://www.drools.org/ (Accessed: 11 December 2019).

Khurana, L. et al. (2016) 'Patient preference for using computers, smartphones, and internet to participate in COPD clinical trials', European Respiratory Journal, 48, p. PA2899.

Larson, E. C. et al. (2013) 'SpiroSmart: Using a Microphone to Measure Lung Function on a Mobile Phone', Proceedings of the 2012 ACM Conference on Ubiquitous Computing - UbiComp '12, 4(2012). doi: 10.1145/2370216.2370261.

Majumder, S. and Deen, M. J. (2019) 'Smartphone sensors for health monitoring and diagnosis', Sensors (Switzerland). MDPI AG, pp. 1-45. doi: 10.3390/s19092164.

MIR (no date) Smartone. Available at: https://www.spirometry.com/ENG/Products/smartone.asp.

Oinas-kukkonen, H. (2009) 'Persuasive Systems Design : Key Issues, Process Model, and System Features Persuasive Systems Design : Key Issues, Process Model, and System Features I INTRODUCTION', Persuasive Systems Design: Key Issues, Process Model, and System Features, 24(March 2009), pp. 485-500.

Pinho, B. et al. (2018) 'Automatic Quality Assessment of Smart Device Microphone Spirometry', in Proceedings of the 8th International Joint Conference on Pervasive and Embedded Computing and Communication Systems. SCITEPRESS - Science and Technology Publications, pp. 115-122. doi: 10.5220/0006866701150122.

Roth, G. A. et al. (2018) 'Global, regional, and national age-sex-specific mortality for 282 causes of death in 195 countries and territories, 1980-2017: a systematic analysis for the Global Burden of Disease Study 2017', The Lancet. Lancet Publishing Group, 392(10159), pp. 1736-1788. doi: 10.1016/S0140-6736(18)32203-7.

Sá-Sousa, A. et al. (2019) 'Adult Asthma Scores-Development and Validation of Multivariable Scores to Identify Asthma in Surveys', Journal of Allergy and Clinical Immunology: In Practice. American Academy of Allergy, Asthma and Immunology, 7(1), pp. 183-190.e6. doi: 10.1016/j.jaip.2018.06.024.

Simpson, A. J. et al. (2017) 'Perspectives of patients and healthcare professionals on mHealth for asthma self-management', European Respiratory Journal. European Respiratory Society. doi: 10.1183/13993003.01966-2016.

States, U. and Resapp (2017) ResAppDX. Available at: https://www.resapphealth.com.au/positive-results-from-australianprospective-clinical-study-confirm-resapps-algorithms-deliver-high-accuracy-when-diagnosing-respiratory-diseasein-adults (Accessed: 3 December 2019).

Thap, T. et al. (2016) 'High-resolution time-frequency spectrum-based lung function test from a smartphone microphone', Sensors (Switzerland), 16(8). doi: 10.3390/s16081305.

Tinschert, P. et al. (2017) 'The Potential of Mobile Apps for Improving Asthma Self-Management: A Review of Publicly Available and Well-Adopted Asthma Apps', JMIR mHealth and uHealth. JMIR Publications Inc., 5(8), p. e113. doi: 10.2196/mhealth.7177.

Tran, H. A., Ngo, Q. T. and Pham, H. H. (2015) 'An application for diagnosing lung diseases on Android phone', ACM International Conference Proceeding Series, 03-04-Dece, pp. 328-334. doi: 10.1145/2833258.2833289.

Vieira-Marques, P. et al. (2020) 'Combined Image-Based Approach for Monitoring the Adherence to Inhaled Medications', in IFMBE Proceedings - MEDICON 2019, pp. 1399-1404. doi: 10.1007/978-3-030-31635-8_171.

Vieira, A. et al. (2019) 'Defining an Architecture for a Coaching Module to Support Self-Monitoring of Chronic Obstructive Respiratory Diseases', in Studies in Health Technology and Informatics. IOS Press, pp. 130-133. doi: 10.3233/SHTI190034.

Watson, H. A., Tribe, R. M. and Shennan, A. H. (2019) 'The Role of Medical Smartphone Apps in Clinical Decision-Support: A Literature Review', Artificial Intelligence in Medicine. Elsevier B.V., p. 101707. doi: 10.1016/j.artmed.2019.101707. 